\title{
A Monte Carlo simulation model for assessing the risk of introduction of Gyrodactylus salaris to the Tana river, Norway
}

\author{
L. G. Paisley ${ }^{1, *}$, E. Karlsen ${ }^{2}$, J. Jarp ${ }^{1}$, T. A. Mo ${ }^{1}$ \\ 'National Veterinary Institute, PO Box 8146 Dep., N-0033 Oslo, Norway \\ ${ }^{2}$ Norwegian Animal Health Authority, Regional Office for Troms and Finmark, PO Box 652, N-9401 Harstad, Norway
}

\begin{abstract}
The Tana river in northern Norway, the most productive salmon river in Europe, is free of Gyrodactylus salaris. Currently there is one salmon farm in operation on the Tana fjord. Because of the strong association between stocking of rivers with salmon and infestations with $G$. salaris there is national and international concern that the existing farm might lead to the introduction of the parasite to the Tana river. In response to these concerns a quantitative analysis of the risk of introduction of $G$. salaris to the Tana river was undertaken. A scenario tree, the Monte Carlo simulation model and results of the simulations including sensitivity analyses are presented and discussed. Results show that the probability of introduction of $G$. salaris to the Tana river via transfer of smolt to the existing salmon farm is extremely low primarily due to the low probablity that the transferred smolt become infested. The total risk was very sensitive to changes in the salinity of the water at the sea site.
\end{abstract}

KEY WORDS: Gyrodactylus salaris Atlantic salmon - Norway Risk assessment Monte Carlo simulation model

\section{INTRODUCTION}

Gyrodactylus salaris (Monogenea), an ecto-parasite of salmonids, causes significant losses in both wild and farmed Atlantic salmon presmolt stocks. The parasite was first reported in Norway in 1975 and to date it has been found there in 40 salmon rivers and 38 farms (Direktoratet for Naturforvaltning 1995). Eleven of the farms raise salmon and 27 raise rainbow trout. An association between stocking rivers with smolt from infected hatcheries and the geographical distribution of the parasite has been demonstrated (Johnson \& Jensen 1986). Because of the serious economic and environmental impacts of the parasite, several procedures and regulations have been instituted in efforts to prevent the further spread of the parasite and to eradicate it from infected rivers and farms. To eradicate $G$. salaris, rivers are treated with rotenone which kills the fish and consequently the parasite (Directoratet for Naturforvaltning 1995, Johnsen et al. 1989, Johnsen \&

\footnotetext{
·E-mail: larry.paisley@vetinst.no
}

Jensen 1991) As a result of rotenone treatments, 23 of 40 infested rivers and all farms are now free of $G$. salaris (Directoratet for Naturforvaltning 1995, Mo unpubl.).

The consequences of Gyrodactylus salaris infestations are severe. Two years after introduction of $G$. salaris the number of young salmon in infested rivers decreased by about $50 \%$, and after 5 to 6 yr only 2 to $5 \%$ survived past the second or third winter (Johnsen \& Jensen 1992). Estimated yearly total losses of 250 to 350 tons of salmon for both sea and river fishing catches have been reported (Johnsen \& Jensen 1985, Dolmen 1987). Additional losses due to damage to sport fishing and the costs of surveillance, control and eradication of the parasite must also be considered.

The Tana river, in northern Norway, the most productive river in Europe in terms of tonnage of wild and farmed salmon harvested (Fylksmannen i Finnmark unpubl., cited in Fylkesveterinceren for Troms og Finnmark 1996), is free of Gyrodactylus salaris. At present, there is one salmon farm in operation on the Tana fjord but an additional farm has been contemplated. There 
have been national and international fears that the existing farm or a future farm might lead to the introduction of the parasite to the Tana river. In response to these fears, a quantitative assessment of the probability of introduction of $G$. salaris to the native Tana river salmon via the introduction of smolt to the commercial farm in the Tana Fjord was undertaken.

\section{METHODS}

A scenario tree depicting the events that would have to occur in order for Gyrodactylus salaris to be introduced to the Tana river was constructed (Fig. 1). The

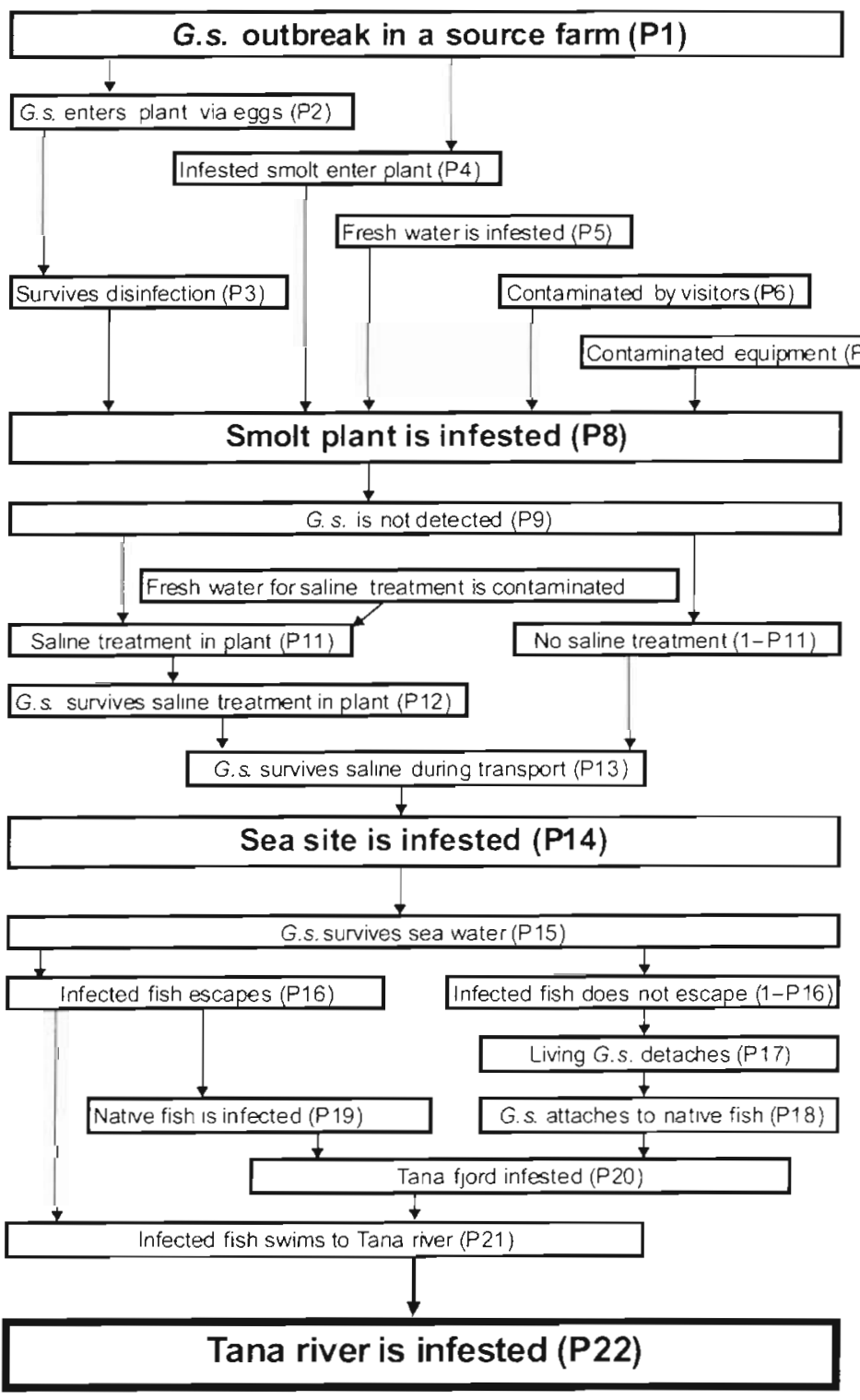

Fig. 1. Scenario tree for the introduction of Gyrodactylus salaris (G. s.) to the Tana river initiating event in the scenario is the occurrence of a new infestation of a salmon hatchery by $G$. salaris. Eggs from a single source are introduced into the smolt plant, where they are hatched and develop to smolt. The smolt are transferred to the sea site in tanks by trucks. The smolt are released into pens at the sea site and grow until harvested. Infestation of the fjord could occur by escape of infested fish or the detachment of living $G$. salaris and re-attachment to a feral fish. The final event in the scenario is the infestation of the Tana river. Each of the steps in the scenario was assigned a probability distribution function or probability of occurrence from which the total risk per transfer of smolt was estimated.

The model was developed with the Excel spreadsheet (Microsoft Corporation, Seattle, WA, USA) with @Risk, a risk analysis software add-on (Palisade Corporation, Newfield, NY, USA). The sampling method was Latin hypercube and the Standard Recalc was Monte Carlo. Each simulation was run for 10000 iterations. Sensitivity of the output values to variations in the input values was assessed by calculating the rank order correlation coefficientswith @Risk. The results are presented as a tornado chart (Vose 1996). Figs. $2 \& 3$ show the spreadsheet model with the formulae and values used for the calculations.

The following variables and probabilities were used to construct the simulation model (Vose 1996, Winston 1996). The notations for probability distribution functions provided by $@$ Risk are written beginning with the letters 'Risk', e.g. RiskPoisson which indicates that a Poisson distribution will be sampled to generate the values in this cell.

Probability of a Gyrodactylus salaris infestation in a source farm that produces salmon eggs or smolt (P1). A Poisson distribution can be used to estimate the distribution of the number of events per unit of time based on the mean number of observed events per unit of time (Vose 1996). A source farm was defined as any potential source of eggs or smolt. The number of a source farms that are newly infested (Sfi) per year was estimated as RiskPoisson (11/23) because there had been 11 infestations of farms that produced eggs and smolt for other farms or smolt plants in the 23 yr since $G$. salaris was first reported in Norway (Mo unpubl.) This function generated a distribution of the number of new infestations that would be expected each year. The minimum, mean and maximum values of the distri- 
Fig. 2. Upper part of the spreadsheet showing the construction and formulas

\begin{tabular}{|c|c|c|}
\hline$\square$ & A & B \\
\hline 1 & RISK MODEL For G. salaris in the Tana River, Norway & \\
\hline 3 & Probability of a GS infestation in a salmon egg or smolt source farm (P1) & \\
\hline $\begin{array}{l}4 \\
5\end{array}$ & $\begin{array}{l}\text { Number of new infestations per year (Sfi) } \\
\text { Number of smolt farms (Nf) }\end{array}$ & $\begin{array}{l}=\text { Risk Polsson }(11 / 23) \\
418\end{array}$ \\
\hline 6 & True prevalence of GS infested farms $\left(T_{p}\right)$ & $=R \mid s k B e t a(B 4+1, B 5-B 4+1)$ \\
\hline 7 & Probability that infested eggs enter the smolt plant $(P 2)$ & $=R I s k B \operatorname{lnomial}(1 . \mathrm{B} 6)$ \\
\hline 8 & Effectivity of disinfection & 0.9 \\
\hline 9 & Percentage of viable GS after 1 disinfection & $=1-B 8$ \\
\hline 10 & Number of disinfections & 3 \\
\hline 11 & Probability of viable GS after 3 disinfections & $=89 \wedge 3$ \\
\hline 12 & Probability that GS survives disinfection in the smolt plamt $(P 3)$ & $=\mathrm{B} 7 \cdot \mathrm{B} 11$ \\
\hline 13 & Probability that GS infested smolt enter the smolt plant $(P 4)$ & 0.000001 \\
\hline 14 & Probability that GS infested fresh water enters the smolt plant (P5) & $=86 /\left(1^{\circ} 10^{\wedge} 4\right)$ \\
\hline 15 & Probability of introduction of GS by visitors $(P 6)$ & 0.000001 \\
\hline 16 & Probability of infestation by contaminated equipment $(P 7)$ & 0.000001 \\
\hline 17 & & \\
\hline 18 & Probability that the smolt plant becomes infested (P8) & $=B 12+B 13+B 15+B 16 \cdot B 14$ \\
\hline 19 & & \\
\hline 21 & Total fish in the smoit plant $(F n)$ & 10000000 \\
\hline 22 & Prevalence of GS in the smolt plant (Pij & $=\bar{R}$ iskindepC (firsti i + RiskUniform $(0,1)$ \\
\hline 23 & Number of fish tested (Nf) & 15 \\
\hline 24 & Test sensitivity (Se) & $=\overline{R i s k D e p C(" f i r s t ", 0.8)+R \text { iskPert(0.05,0.4.0.8) }}$ \\
\hline 25 & Probability that GS is not detected at each test: & 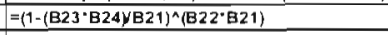 \\
\hline 26 & Total number of tests: & $=$ ROUND,RiskTriang(1,6,18),0) \\
\hline 27 & Probability of no detection of GS during routine health control (P9) & $=(\mathrm{B} 25)^{\prime}(\mathrm{B} 26)$ \\
\hline 28 & Probability of Gs after inspections & $=\mathrm{B} 18^{\circ} \mathrm{B} 27$ \\
\hline 29 & Probability that freshwater for saline treatment in plant is infested (P10) & $=\mathrm{B} 14$ \\
\hline 30 & & \\
\hline 31 & Saline treatment is done at smolt plant: $1=$ ves, $0=n o(P 11)$ & $=$ RiskSimtable $(\{1,0\}\}$ \\
\hline 32 & & \\
\hline 33 & Probability that GS survives saline treatment in the smolt plant (P12) & $=\mid F\left(B 31=1,\left(0.00000001^{\prime} B 28\right)_{h} B 28\right)$ \\
\hline 34 & Probability that GS infested freshwater is used in saline treatment $(P 10)$ & $=829^{-1}$ \\
\hline 35 & Probability of GS alive after saline & $=B 33+B 34$ \\
\hline 36 & Probability that GS survives transport in saline to the sea site (P13) & $=835^{\circ} 0.75$ \\
\hline 37 & & \\
\hline 38 & Probability that the sea site is infested (P14) & $=\mathrm{B} 36$ \\
\hline 40 & Probability for escape of fish within 240 hours ( $P$ e) & $=$ RiskUniform $(0,0.00235)$ \\
\hline 41 & & \\
\hline 42 & $\begin{array}{l}\text { Probability that a fish with living GS escapes from the net (P15) } \\
\text { Time of escape } 0-240 \text { hrs (Te) }\end{array}$ & $=I F(B 44>B 43,1,0)$ \\
\hline 43 & & $=R I S k P e r(0.24 .240)$ \\
\hline 44 & Maximum survival time@1.4C $0.33-240$ hours (Mts) & $=E 84$ \\
\hline 45 & Probability that GS will be transmitted to wild fish in the river $(P i)$ & 1 \\
\hline 46 & Probability that GS will be transmitted to wild fish via escape (P16) & $=838^{\circ} 840^{\circ} \cdot 342^{*} B 45$ \\
\hline 47 & Probability that infected fish swims to Tana River (P21) & $=B 38^{\circ} B 40^{*}\left(B 42^{*}\left(R / 5 k^{T}\right.\right.$ Triang $\left.\left.(0,0.5,1)\right)\right\}$ \\
\hline 48. & & \\
\hline 49 & Probability of introduction of GS to the sea site (P13) & $=$ B38 \\
\hline 50 & Maximum survival time @ $1.4 \mathrm{C}$ is $0.33-240$ hours (Mts) & $=844$ \\
\hline 51 & Time of detachment $0-240$ hours $(T d)$ & $=$ RiskUniform $(0,240)$ \\
\hline 52 & Probability that live $G S$ will be detached $(P 17)$ & $=\mid F(B 50>B 51,1,0)$ \\
\hline 53 & Probability that a de tached GS will hit a free fish outside the net $(P h)$ & 0.001 \\
\hline 54 & Probability that GS will attach to a free fish $(P a)$ & 0.5 \\
\hline 55 & Probability that GS will be trans mitted to wild fish in the river (P18) & $=853^{\circ} \cdot 854$ \\
\hline 56 & Probability that GS will attach to wild fish (P19) & $=\left(B 49^{\circ} \mathrm{B} 52^{\prime} \mathrm{B} 55\right)$ \\
\hline 57 & Probability Tana Fjord is infested via detachment $(P 20)$ & $=849^{\circ} \cdot 856$ \\
\hline 58 & Total risk per transport of fish to the Tana River (P22) & $=\mathrm{B} 46+\mathrm{B} 47+\mathrm{B} 56$ \\
\hline
\end{tabular}

\begin{tabular}{|c|c|c|c|c|}
\hline$\frac{\bar{a}}{7 \overline{1} \text { Salinity }}$ & |survival time & Gradient & intêrcept & Equation \\
\hline 7210 & 240 & $=\operatorname{SLOPE}(\mathrm{B} 72: \mathrm{B} 73, \mathrm{~A} 72: \mathrm{A} 73)$ & $=1$ INTERCEPY (B72:B73A72:A73) & 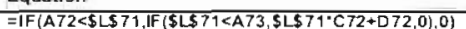 \\
\hline 7315 & 78 & $=\operatorname{SLOPE}(B 73: B 74, A 73: A 74)$ & $=$ INTERCEPT $(B T 3: B 74, A 73: A 74)$ & $=I F\left(A 73<\$ L 571, \mid F\left(\$ L \$ 157<A 74, \$ L \$ 71^{\circ} \mathrm{C} 73+073,001,0\right)\right.$ \\
\hline $74 \mathbf{2 0}$ & 42 & $=S L O P E(B 74: B 75, A 74: A 75)$ & IINTERCEPT(B74:B75,A74:A75) & $=\mid F\left(A 74<\$ L \$ 71, \mid F\left(\$ L S 71<A 75, \$ L 571^{\circ} C 74+D 74,0\right), 0\right)$ \\
\hline $75 \mid 30$ & $=A 74^{\circ} B_{776 / A 76} B 744$ & $=\operatorname{SLOPE}(\mathrm{B} 75: \mathrm{B} 76, \mathrm{~A} 75: \mathbf{A} 76)$ & =INTERCEPT $(B 75: B 76, A 75: A 76)$ & $|=| F\left(A 75<\$ L \$ 71, \mid F\left(\$ L \$ 11<A 76, \$ L 571^{\circ} \mathrm{C} 75+D 75,0\right), \mathbf{0}\right)$ \\
\hline $76 ! 33$ & 0.33 & & & \\
\hline 77 & & & & \\
\hline 78 & & & & \\
\hline 79 ;Salinnty & $\mid x$ & $\mathrm{~F}(\mathbf{X})$ & & Salinity \\
\hline 80110 & 10 & 10 & & $\mid=$ RiskCumul(9,37,\$AS80: 5 A $\$ 105, \$ C \$ 80: 5 C \$ 105)$ \\
\hline 81 11 & 1 & 0.0263157894736842 & & \\
\hline $82 \quad 12$ & 10 & 0.0263157894736842 & & \\
\hline & 10 & 0.0263157894736842 & & Survival time \\
\hline & $0^{-}$ & 0.0263157894736842 & & =SUM(E72:E75) \\
\hline & 1 & 0.0526315789473684 & & \\
\hline & 1 & 0.0789473684210526 & & \\
\hline & 3 & 0.157894736842105 & & \\
\hline & $2^{-}$ & 0.210526315789474 & & \\
\hline & 1 & 0.236842105263158 & & \\
\hline & 3 & 0.315789473684211 & & \\
\hline 9121 & 0 & 0.315789473684211 & & \\
\hline 9222 & 1 & 0.342105263157895 & & \\
\hline 9323 & 1 & $0.3684 \overline{21} 1052631579$ & & \\
\hline$9 4 \longdiv { 2 4 }$ & $0^{-}$ & 0.368421052631579 & & \\
\hline 9525 & 5 & & & \\
\hline 9626 & 1 & 0.526315789473684 & & \\
\hline 9727 & 1 & 0.552631578947368 & & \\
\hline $98 \mathbf{2 8}$ & 0 & 0.552631578947368 & & \\
\hline$9 9 \longdiv { 2 9 }$ & 1 & 0.578947368421053 & & \\
\hline 10030 & 6 & 0.736842105263158 & & \\
\hline 10131 & 3 & 0.815789473684211 & & \\
\hline 10232 & 5 & 0.947368421052632 & & \\
\hline $103 \mid 33$ & 1 & 0.973684210526316 & & \\
\hline 10434 & 0 & 0.973684210526316 & & \\
\hline 10535 & 1 & 1 & & \\
\hline
\end{tabular}

106
Fig. 3. Lower part of the spreadsheet show-

ing the construction and formulas 
bution were, $0,0.47$ and 5, respectively. The number of farms that produce eggs and smolt in Norway is 418 . The distribution of the probability $(\mathrm{p})$ of occurrence of an event based on the number of occurrences that were observed in a known number of opportunities can be estimated with a beta distribution (Vose 1996). True prevalence ( $\mathrm{Tp}$ ) is the probability that a farm is infested. Tp of infestation in source farms was modeled as RiskBeta ( $\mathrm{Sfi}+1,418+1$ ). This generated a distribution of $\mathrm{Tp}$ with a minimum of $5.66 \mathrm{E}-07$, a mean of 3.51E-03 and a maximum of 2.71E-02.

Probability that Gyrodactylus salaris enters the smolt plant via eggs (P2). The probability that the source of eggs for this specific smolt plant was infested was estimated by RiskBinomial (1, Tp). This distribution will generate $a \quad 0$ if the eggs are not from an infested source farm and $a 1$ if the source farm is infested. The percentage of times that a 1 is generated is the probability that eggs from an infested farm (and perhaps $G$. salaris) enter the smolt plant.

Probability that Gyrodactylus salaris survives disinfectant treatment in the smolt plant (P3). The maximum survival time for a free-living $G$. salaris is approximately 1 wk (Fylkesveterinæren for Troms og Finmark 1996). Based on experimental studies on the effects of iodine solutions on $G$. salaris (Mo unpubl.), it was estimated that each treatment with the iodine solution would be at least $90 \%$ effective in killing $G$. salaris. It was assumed that each batch of eggs would be treated 3 times. Therefore, the risk of survival after disinfection was estimated by P2 $(1-0.9)^{3}$.

Probability that Gyrodactylus salaris iniested smolt enter the smolt plant (P4). The probability of infested smolt entering this smolt plant was estimated to be $0.0 \%$ because of the regulation prohibiting the entry of live smolt. Only eggs are allowed to be introduced into this smolt plant. However, a value of $1 \mathrm{E}-08$ was used in the model because 0 risk is unattainable and it is lower than 1E-06, which is considered 'negligible risk or no significant risk' in human health and environmental risk studies (Ahl et al. 1993).

Probability that Gyrodactylus salaris infested fresh water enters the smolt plant (P5). This was estimated as $\mathrm{P} 2 / 10^{4}$. If there were a source of infestation in the fresh water the probability could not be greater than the risk that the source of the eggs was infested. Because there are no susceptible hosts in the fresh water supplying the smolt plant the risk was arbitrarily reduced by a factor of 1.0E-04

Probability that visitors contaminate the smolt plant with Gyrodactylus salaris (P6). This was estimated to be zero $(0.0 \%)$ because contamination by visitors would almost have to be a deliberate act and access to the plant by visitors is severely restricted. The actual value used in the model was $1 \mathrm{E}-08$.
Probability of infection by contaminated equipment (P7). This probability was estimated as $0.0 \%$ because there is no sharing of equipment between plants or between areas within the plant. The actual value in the model was 1 E-08.

Probability that the smolt plant is infested (P8). The overall probability of infestation of the smolt plant was calculated according to the formula: $\mathrm{P} 8=(\mathrm{P} 1 \cdot \mathrm{P} 2 \cdot \mathrm{P} 3)+$ $\mathrm{P} 4+\mathrm{P} 5+\mathrm{P} 6+\mathrm{P} 7$.

Probability that Gyrodactylus salaris is not detected during routine health inspection in the smolt plant (P9). A routine health inspection in the smolt plant consists of gross visualization and microscopic examinations of scrapings from 15 fish. The fish undergo inspections 1 to 18 times during the hatching/growing phase. The sensitivity of the procedures in detecting $G$. salaris is dependent on the prevalence of infested fish, the number of parasites on each fish and the number of times the fish are tested. The sensitivity of the routine examinations was estimated to be near $0 \%$ very early but near $100 \%$ at later stages when all fish are affected by many parasites. The prevalence of infected fish (Pi) was estimated by RiskUniform $(0,1)$. This function generated a probability distribution with a minimum of $6.74 \mathrm{E}-05$, a mean of 0.5 and a maximum of $99.99 \%$. The sensitivity of the test procedures (Se) was estimated as a minimum of $5 \%$, most likely $40 \%$ and a maximum of $80 \%$. This was modeled by RiskPert $(0.05,0.40,0.80)$ (Vose 1996). Since the sensitivity of the examination procedure is dependent on the prevalence of infested fish, sensitivity was correlated with the prevalence with a coefficient of 0.8 (Vose 1996). Therefore, P9 was calculated as $1-(\mathrm{Pi} \cdot \mathrm{Se})$.

Probability that fresh water used for saline treatment is infested (P10). The $2.0 \%$ saline solution used to treat the smolt is made by mixing salt with fresh water. The source of the water is the same as for the rest of the plant. Therefore, the probability (P10) is the same as P5.

Saline treatment is or is not done in the plant (P11). Two simulations of 10000 iterations each were done. If saline treatment was done a value of 1 was generated by the @Risk function, RiskSimtable $(\{1,0\})$. If no saline treatment was done the value generated was 0 . These 2 values were used in the calculation of P12.

Probability that Gyrodactylus salaris survived saline treatment in the smolt plant (P12). The probability that $G$. salaris survives the saline treatment in the plant prior to shipment, given that the saline treatment was done, was estimated as 1E-08 because the maximum survival time of $G$. salaris in $2.0 \%$ saline solution at $1.4^{\circ} \mathrm{C}$ is $4.6 \mathrm{~h}$. Survival time shortens as water temperature increases (Soleng \& Bakke 1997). The inplant saline treatment is a minimum of $168 \mathrm{~h}$ at ambi- 
ent temperature which is above $1.4^{\circ} \mathrm{C}$. The value of $\mathrm{P} 12$ was set to $1 \mathrm{E}-08$ if saline treatment was done as in Simulation \#1 and 1 if no saline treatment was done as in Simulation \#2.

Probability that Gyrodactylus salaris survives saline treatment during transport to the sea site (P13). The smolt are transported to the sea site by truck in tanks containing $2.0 \%$ saline solution. However, the transport time is less than $4 \mathrm{~h}$ so that the probability of survival was arbitrarily set at $75 \%$, a conservative figure.

Probability that Gyrodactylus salaris infested smolt are released at the sea site (P14). The total probability that infested smolt are released at the sea site is: $\mathrm{P} 14=$ $(\mathrm{P} 8 \cdot \mathrm{Pg} \cdot \mathrm{P} 11 \cdot \mathrm{P} 12)+\left(\mathrm{P} 10^{*} \mathrm{P} 12\right)$

Probability of escape from the pen (Pe). The probability of escape from the pen was estimated by RiskUniform $(0,0.00235)$ based on the number of escapes occurring during the first $10 \mathrm{~d}$ after release in sea pens per number of releases (Fylkesveterinæeren for Troms og Finnmark 1996). This generated a probability distribution with a minimum of 1.03E-07, mean of 1.17E-04 and a maximum of 2.35E-03. The probability of no escape was $(1-\mathrm{Pe})$

Probability that a fish with living Gyrodactylus salaris escapes from the pen (P15). The distribution for the maximum time of survival (Mts) of $G$. salaris in the salinity at the sea site was estimated as follows: Salinity measurements were taken at the sea site over a $45 \mathrm{~d}$ period during which transfer of smolt takes place. These measurements were used to produce a cumulative probability distribution of the salinity, RiskCu$\operatorname{mul}\{9,37,\{x\},\{p\})$ (Vose 1996).

The maximum survival times in $1.0,1.5,2.0$ and $3.3 \%$ saline solutions at $1.4^{\circ} \mathrm{C}$ (Soleng \& Bakke 1997) were used to develop linear functions describing the slope and intercept of each separate segment of the 'survival curve' such that for any salinity value generated an Mts at $1.4^{\circ} \mathrm{C}$ was calculated (Vose pers. comm.).

The time of escape ( $\mathrm{Te}$ ) was calculated as follows. Escapes can occur anytime after transfer. The time of transfer was set at $0 \mathrm{~h}$. It was assumed that most escapes would occur during the first $24 \mathrm{~h}$ after transfer. Fish escaping more than $240 \mathrm{~h}$ after transfer to sea water would be unlikely to harbor living Gyrodactylus salaris (Soleng \& Bakke 1997). Therefore, Te was calculated with the function RiskPert $(0,24,240)$. This generated a distribution with a minimum of $1.75 \mathrm{E}-02$, a mean of 55.99 and a maximum Te of $216.7 \mathrm{~h}$.

If Mts was greater than Te the value generated for P15 was 1; otherwise the value was 0 . The probability that a fish with living Gyrodactylus salaris escaped the pen (P15) was the percentage of times that a value of 1 was generated.
Probability that Gyrodactylus salaris is transmitted to a wild fish in the river (Pi). If a fish with living $G$. salaris escaped from the pen the probability that the Tana fjord and, ultimately, the Tana river is infested (Pi) was set at $100 \%$

Probability that Gyrodactylus salaris is transmitted to wild fish via escape (P16). This was calculated as: $\mathrm{P} 14 \cdot \mathrm{Pe} \cdot \mathrm{P} 15^{*} \mathrm{Pi}$.

Probability that a living Gyrodactylus salaris detached from an infested salmon (P17). The probability that a $G$. salaris would detach was set to $100 \%$. If the parasite was dead by the time of escape this value was $0 \%$. The Mts was calculated as explained in P15. The time of detachment (Td) was calculated with RiskUniform $(0,240)$ where detachment could occur with equal probability any time between the time of release (0) and $240 \mathrm{~h}$, the maximum period of risk. If Mts was greater than $\mathrm{Td}$ a value of 1 was generated. If Mts was greater than Te the value generated for P17 was 1 ; otherwise the value was 0 . Thus, the probability that a fish with living $G$. salaris escaped the pen (P15) was the percentage of times that a value of 1 was generated. The probability that $G$. salaris would detach and sink through the pen to the sea bottom during the first 240 h was estimated as $100 \%$.

Probability that a living Gyrodactylus salaris attaches to a native salmon (P18). The probability that a detached $G$. salaris encounters a native salmon swimming under the pen (Ph) was estimated as $1.0 \mathrm{E}$ 03 based on the estimated relative numbers of fish inside and under the pen. The probability of attachment $(\mathrm{Pa})$ was estimated as 0.5 . Thus, P18 equaled $\mathrm{P} 17^{*} \mathrm{Ph}$ *Pa.

Probability that Gyrodactylus salaris will infest a native salmon (P19). The probability that an escaped salmon with living $G$. salaris attached would encounter and infect a native salmon was calculated as 1.0E-02. This value was set higher than the probability that a detached $G$. salaris would encounter and attach to a native salmon because of the ability of the infected fish to travel away from the pen.

Probability that the Tana fjord would be infested with Gyrodactylus salaris via detachment (P20). The total probability (risk) of infestation of the Tana river by $G$. salaris via detachment was calculated as P13*P19.

Probability that an infected salmon would swim directly to the Tana river (P21). The probability distribution function RiskUniform $(0,1)$ was used to model the probability that an escaped, infested salmon migrates to the Tana river. This function was chosen because there was no information regarding this probability. This generated a distribution with a minimum probability value of $4.12 \mathrm{E}-03$, a mean of 0.5 and a maximum of 0.993 . 
Table 1. Risk of introduction of Gyrodactylus salaris to the Tana river per trans-

\begin{tabular}{|c|c|c|c|c|}
\hline & Minimum & Mean & Maximum & 95th percentile \\
\hline \multicolumn{5}{|c|}{ Probability of plant infestation } \\
\hline Simulations \#1 and \#2 & $3.06 \mathrm{E}-06$ & $6.85 \mathrm{E}-06$ & $1.00 \mathrm{E}-03$ & $4.02 \mathrm{E}-06$ \\
\hline \multicolumn{5}{|c|}{ Probability of sea site infestation } \\
\hline Simulation \#1 & $5.97 \mathrm{E}-12$ & $2.63 \mathrm{E}-07$ & $2.70 \mathrm{E}-06$ & $7.52 \mathrm{E}-07$ \\
\hline Simulation \#2 & $5.97 \mathrm{E}-12$ & $4.97 \mathrm{E}-07$ & $6.63 \mathrm{E}-04$ & $1.28 \mathrm{E}-06$ \\
\hline \multicolumn{5}{|l|}{ Total risk per transfer } \\
\hline Simulation \#1 & 0 & 1.60E-10 & $5.14 \mathrm{E}-09$ & $9.02 \mathrm{E}-10$ \\
\hline Simulation \#2 & 0 & 2.33E-10 & $1.74 \mathrm{E}-08$ & 1.26E-09 \\
\hline
\end{tabular}
fer of smolt

for Simulation \#1 revealed that the salinity at the sea site was the factor with the highest correlation $(-0.595)$ with the risk of introduction of Gyrodactylus salaris (Fig. 5). That is, the higher the salinity the lower the risk. Other factors, listed in descending order of correlation, included: time of escape, time of detachment, prevalence of $G$. salaris infected farms, probability of escape, the number of new infestations per year, the probability an infected fish swam to the Tana river. whether infected eggs entered the plant. the prevalence of $G$. salaris in the plant,

Probability that Tana fjord is infested with Gyrodactylus salaris by a single transfer of smolt (P22). This was calculated as P19+P20 + P21.

\section{RESULTS}

The results are presented in Table 1 . Simulation \#1 is with saline treatment of the smolt prior to transfer and Simulation \#2 is without saline treatment. The results are also shown as cumulative probability distributions in Fig. 4. The results show that the risk of infestation of the Tana river by Gyrodactylus salaris via introduction of salmon smolt to this specific sea site is extremely low. In Simulation \#2, when saline treatment was not done, the maximum risk calculated in any of the 10000 iterations was $1.74 \mathrm{E}-08$. In $65 \%$ of the iterations in both simulations the risk was estimated as $0 \%$. In $95 \%$ of the iterations the risk was less than or equal to 9.02E-10 and 1.26E-09 in Simulations \#1 and \#2, respectively. In addition, approximately $78 \%$ of the values were less than or equal to the mean value of both simulations.

Sensitivity analysis was done by calculating the rank-order correlation coefficients. Sensitivity analysis the total number of inspections and sensitivity of the inspections.

In Simulation \#2, the results (not shown) were similar except that the sensitivity of the inspection procedure ranked higher than the probability of an infected fish swimming to the Tana river, whether Gyrodactylus salaris entered the plant with eggs and the total number of inspections. The prevalence of $G$. salaris in the smolt plant ranked higher than the test sensitivity. Whether or not saline treatment in the smolt plant was done ranked below all of the above variables in a combined simulation where saline treatment was done in $50 \%$ of the iterations.

\section{DISCUSSION}

Risk assessment is a procedure that is often used when a decision must be made under conditions of uncertainty. Uncertainty can be a result of lack of, or insufficient, knowledge and the variability due to chance. Risk assessment consists of determining what can go wrong, how likely it is to go wrong and the consequences should it occur. The general steps in conducting a risk assessment are to construct a scenario

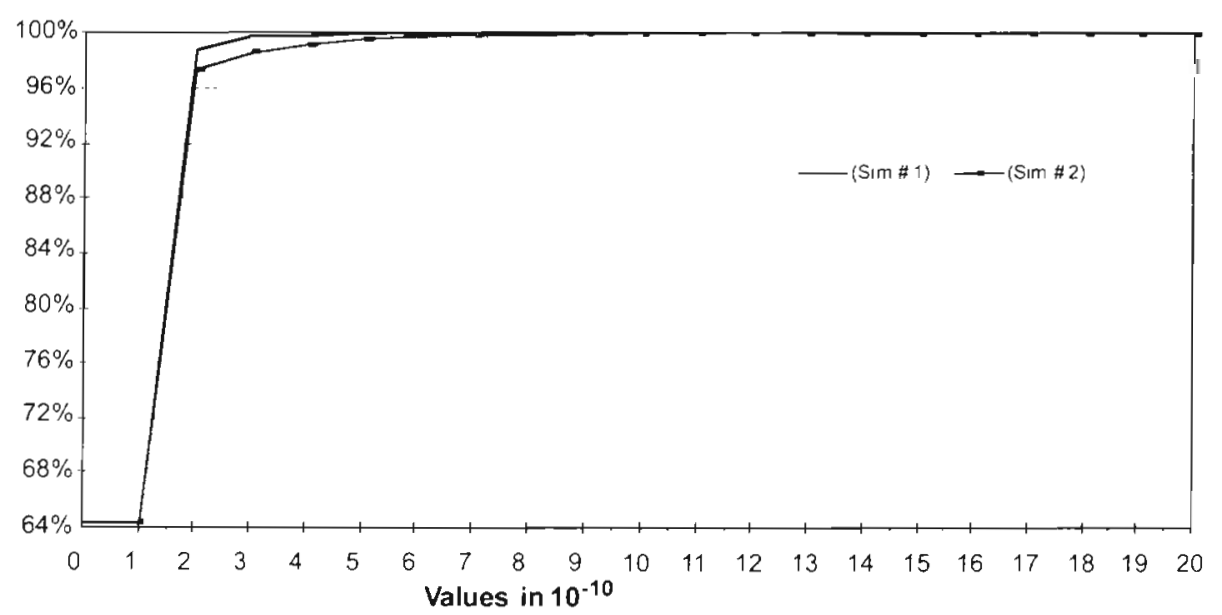

Fig. 4. Cumulative probability distributions for the risk of introduction of Gyrodactylus salaris. The distributions show that the effect of saline treatment in the smolt plant have minimal effect on the total risk per transport of fish. The primary effect of saline treatment is to narrow the range of the risk estimate. The chart also shows that approximately $65 \%$ of the time the calculated risk was $0 \%$ 
Fig. 5. Tornado graph depicting the rank order coefficients between the inputs and the risk of introduction of Gyrodactylus salanis in Simulation \#1 (with saline treatment in the plant). The variables are shown in decreasing order of effect on the output

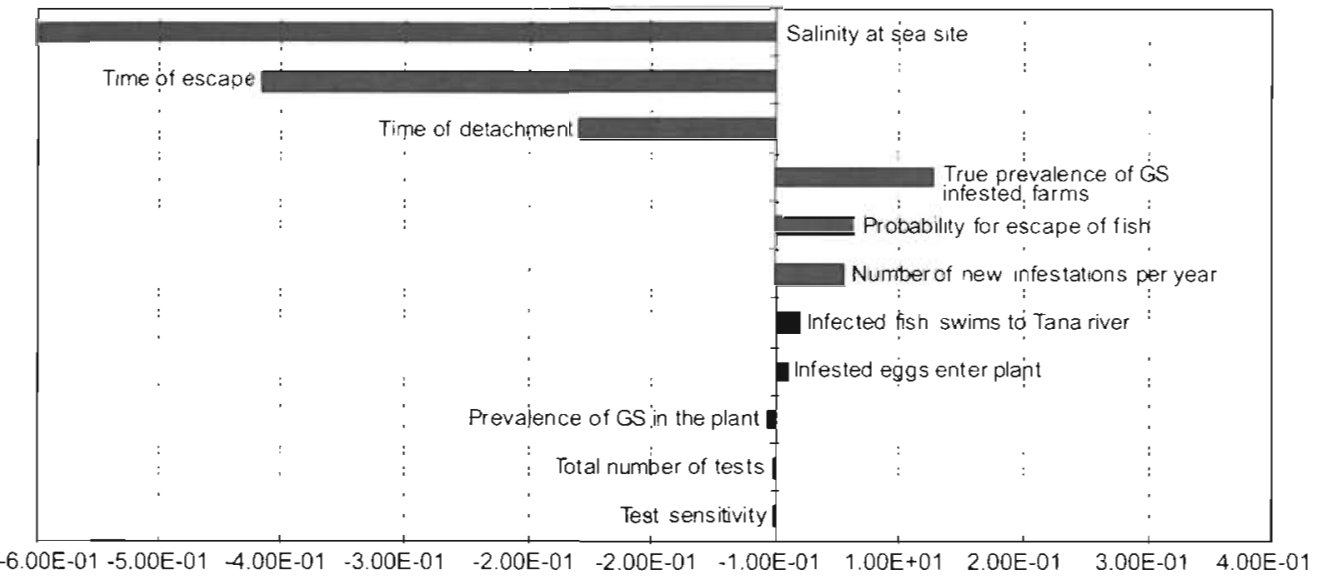

tree or flow diagram identifying the events or steps and pathways from the initiating event to the final outcome, to assign probabilities of occurrence to each event in the process and, finally, to calculate the total risk of occurrence. The assessment of the consequences, should an adverse event occur, should be the next logical step but that is beyond the scope of this project. To ensure that the results are accepted the model should be transparent. That is, every step and probability assigned are explained and justified.

Monte Carlo simulation models (Vose 1996, Winston 1996) are often used to assess risks because they utilize probability distribution functions in lieu of fixed probabilities, in multiple iterations, thus addressing the inherent uncertainties in natural systems. The results generated are probability distributions from which the minimum, maximum, mean and other more familiar parameters for risk can be calculated.

The results of the simulations demonstrate that the risk of introduction of Gyrodactylus salaris to the Tana river by transferring salmon smolt to the sea site is extremely small under the conditions imposed in the models. If any of the conditions should change or any of the assumptions are invalid the results would likely be much different. For example, the risk assessed in this analysis is that associated with smolt from a specific smolt plant where only eggs, and not smolt, are allowed to enter the plant. If the source of eggs were another plant or smolt were allowed to enter the plant the model assumptions would no longer be valid. It is for these reasons that all of the inputs and assumptions in a risk model must be transparent and justified by the best information available at the time. The input variables P4, P6, and P7 are included in the model only to demonstrate that these factors were considered in constructing the model. This allows flexibility so that if new information should surface the 'negligible risk' values of $1 \mathrm{E}-08$ assigned to these variables could be changed to a value reflecting that particular risk.
The importance of treatment of the smolt in $2.0 \%$ saline solution prior to transfer to the sea site, one of the risk reduction measures that has been put into practice, was modeled where treatment was done in $50 \%$ of the iterations. All other variables in the model changed according to their respective probabilities or probability distributions. In the sensitivity analysis, saline treatment in the plant ranked number 7 of the rank-order correlation coefficients, suggesting that this procedure would not greatly reduce the overall risk.

This model incorporated measurements of the salinity of the sea water in the Tana fjord during the period when the smolt are normally released (Gjerp \& Vaskinn 1989). The salinity data were combined with experimental data on the maximum survival time of Gyrodactylus salaris at various water temperatures and salinity levels (Soleng \& Bakke 1997) to generate probability distributions of the survival times of $G$. salaris in relation to the time of escape from the pen or detachment and falling to the bottom. The salinity of the sea water had the highest rank-order correlation with the total risk in all simulations. These results show that ensuring high salinity at the sea site at the time of transfer is the procedure that would reduce the risk by the greatest amount.

The results of this analysis suggest that the risk of introduction of Gyrodactylus salaris to the Tana river via the transfer of smolt from this specific smolt plant is very small. However, these results should not be extrapolated to other plants or other situations where the estimated risk may be quite different. In addition to the value of the quantitated risk estimates generated, the modeling procedure is valuable in itself because it allows greater understanding of the entire system, and identifies information gaps and possible risk management options that can be simulated. The next logical step in the process is the evaluation of the economic, environmental and social consequences should introduction of $G$. salaris occur. 
Risk models should be flexible and dynamic so that they can be revised if and when conditions change or better information becomes available. The results should not be interpreted as 'the answer' but as some of the information a risk manager can consider when arriving at a decision. Simulation modeling is an supplement to, not a substitute for, carefully conducted scientific investigations. It should aiso be emphasized that, in this case, the results are theoretical, probably impossible to validate and depend on humans following the rules. It should also be remembered that low probability events sometimes do occur.

\section{LITERATURE CITED}

Ahl AS, Acree JA, Gipson PA, McDowell RM, Miller L, McElvaine MD (1993) Standardization of nomenclatures for animal health risk analysis. Rev Sci Tech Off Int Epiz 12(4):1045-1053

Dolmen D (1987) Gyrodactylus salaris (Monogenea) in Norway; infestations and management. In: Stenmark $A_{1}$ Malmberg G (eds) Parasites and diseases in natural waters and aquaculture in Nordic countries. Proceedings of a Symposium. Stockholm, p 63-69

Direktorat for Naturforvaltning (1995) Forslag til handlingsplan for tiltak mot lakseparasitten Gyrodactylus salaris for perioden 1995-1999. Utredning for DN 1995-2, Trondheim

Fylkesveterinæren for Troms og Finnmark (1996) Risikoanalyse for spredning av lakseparasitten Gyrodactylus

Editorial responsibility: Wolfgang Körting,

Hannover, Germany salaris fra oppdrettsfisk i Tanfjorden til villfisk med en faglig vurdering for andre fiskesykdommer. Rapport fra projekt gruppen, Juli 1996. Statens Dyrehelsetilsyn Harstad

Gjerp SA, Vaskinn K (1989) Analyse av hydrofysiske forholdinklusive ferskvannstilrenning i Tana og Altafjorden med henblikk på fiskeoppdrett. Norsk hydrotekniske laboratorium, SINTEF, Trondheim, Rapport \#STF60 A89017

Johnsen BO, Jensen AJ (1985) Parasitten Gyrodactylus salaris på laksunger I norske vassdrag, statusrapport. Direktoratet for vilt og ferskvannfisk, Regulingsundersøkelsene, Trondheim. Rapport 12:1-145

Johnsen BO, Jensen AJ (1986) Infestations of the Atlantic salmon, Salmo salar L., by Gyrodactylus salaris Malmberg in the river Lakselva, Misvær in northern Norway. J Fish Biol 40:433-444.

Johnsen BO, Jensen AJ (1991) The Gyrodactylus story in Norway. Aquaculture 98:1-3,289-302

Johnsen BO, Jensen AJ (1992) Infestations of the Atlantic salmon, Salmo salar L., by Gyrodactylus salaris in Norwegian rivers. J Fish Biol 29:233-241

Johnsen BO, Jensen A.J, Sivertsen B (1989) Extermination of Gyrodactylus salaris - infected Atlantic salmon Salmo salar by rotenone treatment in the Vikja, Western Norway. Fauna Norvegica Ser A 10:39-43

Soleng A. Bakke TA (1997) Salinity tolerance of Gyrodactylus salaris (Platyhelminthes, Monogenea): laboratory studies. Can J Fish Aquat Sci 54:1837-1845

Vose D (1996) Quantitative risk analysis: a guide to Monte Carlo simulation modeling. John Wiley \& Sons Ltd, Chichester

Winston WL (1996) Simulation modeling using @Risk. Duxbury, Belmont, CA

Submitted: November 10, 1998; Accepted: March 3, 1999 Proofs received from author(s): July 12, 1999 